\title{
CONSIDERAÇÕES SOBRE A APROPRIAÇÃO DO ESPAÇO MARANHENSE PELO AGRONEGÓCIO DA SOJA: A IDEOLOGIA DO DESENVOLVIMENTO E A ACUMULAÇÃO DE TERRAS NA MICRORREGIÃO DOS GERAIS DE BALSAS
}

\author{
APPROPRIATION DE L'ESPACE POUR LINDUSTRIE AGROALIMENTAIRE \\ MARANHENSE SOYA: L'IDÉOLOGIE DU DÉVELOPPEMENT ET DE \\ L'ACCUMULATION DE TERRES DE LA GERAIS DE BALSAS
}

\author{
CONSIDERATIONS ABOUT APPROPRIATION OF LANDSCAPE \\ BY SOYBEAN AGRIBUSINESS IN THE SOUTHERN PART OF MARANHAO \\ STATE BRAZIL: THE IDEOLOGY OF DEVELOPMENT AND ACCUMULATION \\ OF LAND IN GERAIS OF BALSAS MICRORREGION
}

Sávio José Dias Rodrigues - Universidade Federal do Rio de Janeiro - Rio de Janeiro - Rio de Janeiro - Brasil savio_diasbr@yahoo.com.br

\author{
Francisco Amaro Gomes de Alencar - Universidade Federal do Ceará - Fortaleza - Ceará - Brasil \\ famaro@ufc.br
}

\section{Resumo}

Este trabalho tem como objetivos analisar a expansão do agronegócio da soja na microrregião Gerais de Balsas e 0 aumento da pobreza. Para atingir os objetivos propostos, as reflexões ocorrem sobre a produção do espaço da moderna agricultura da soja, das relações de produção do agronegócio. Buscamos algumas notas para o debate acerca do discurso de que 0 agronegócio traz para o desenvolvimento para a região, a partir de documentos do estado e, principalmente, de investidores públicos, como o BNDES. Os resultados sinalizam que, no Maranhão, se por um lado o IDH, renda per capita e o PIB melhoram, por outro ocorre a concentração de terras e renda pelo grande empresário agrícola, favorecendo o empobrecimento e a expulsão do campesinato.

Palavras-chave: Desenvolvimento, agronegócio, soja, pobreza.

\section{Abstract}

This paper aims to analyze the expansion of soybean agribusiness in the micro-region of Gerais de Balsas and increased poverty. Reflection on the production of space in modern farming of soybeans, the production relations of agribusiness. We seek some notes for the debate about the speech that carries on agribusiness development for the region, from documents of the state, and especially of public investors, such as BNDES. This search points that in Maranhão for one side the IDH, per capita income and the PIB increased, in the other side happened a concentration of the lands and income for the big agribusiness, in detriment of the impoverishment and the expulsion of peasantry.

Key words: Development, agribusiness, soy, poverty.

\section{Résumè}

Cet article prend en compte le processus d'expansion de l'agrobusiness du soja associée l'augmentation de la pauvreté dans la micro-région de Gerais de Balsas. Le point de depart c'est la réflexion sur la production de l'espace de l'agriculture moderne et ses relation de travail. Ayant comme des sources les politiques publiques amennés par le BNDS, on met en evidence les discours employés pour justifier le devellopement de la région. Les 
résultats de la recherche indiquent que le IDH et le PIB on aumenté, mais par contre, on a perçu une concentration des terres avec l'expulsion des paysants.

Mots clés: Dévelloppement, agrobusiness, soja, pauvreté.

\section{Introdução}

O termo desenvolvimento sustentável nasceu das discussões no âmbito das crises capitalistas e com a participação de grandes empresas como foi o caso da reunião do Clube de Roma, base dos debates sobre o desenvolvimento sustentável. Conforme Porto-Gonçalves (2002), essa reunião foi o alicerce da Conferência de Estocolmo em 1972, que por sua vez gerou o relatório "Nosso Futuro Comum”, originando o conceito de desenvolvimento sustentável.

No Estado do Maranhão, a implementação de estratégias de desenvolvimento enfatizou a atual modernidade do modo de produção capitalista. Essa modernidade foi definida em 1993 por Edward Soja como sendo a quarta modernidade do capitalismo que surgiu com a crise no modo de produção, após a década de 1960. Assim, os modelos produtivos foram forçados a se reestruturar, e as principais características que marcaram esse período foram as inserções de tecnologias e a precarização do trabalho.

O amplo quadro de pobreza em que está inserido o Maranhão refletese nos índices de exclusão social. Dentre os cem municípios do Brasil com maiores índices de exclusão social, 35 estão nesse estado, o que leva à necessidade de promover políticas que visem ao desenvolvimento. Porém, as ações no Maranhão podem ser analisadas mais como estruturantes do grande capital do que propriamente de desenvolvimento ou redução da exclusão social.

Essas políticas promovidas pelo estado, que tem a falácia do desenvolvimento, correspondem à integração do Maranhão à economia globalizada. Anacronicamente, vêm-se repetindo as velhas funções das estruturas das relações capitalistas de produção e reprodução da pobreza, a mesma que o planejamento do desenvolvimento alegou sanar, conforme nos lembrou Francisco de Oliveira: "[...] o planejamento num sistema capitalista não é mais que a forma de racionalização da reprodução ampliada do capital" (Oliveira, 1981, p. 24).

A “nova roupagem” em que se dá à reprodução da pobreza é a dos projetos agroindustriais imbricados com o planejamento estatal mara- 
nhense, que visa maximizar os investimentos macroempreendedores, apoiados por um forte discurso desenvolvimentista em que os grandes projetos trariam prosperidade e saída da pobreza, principalmente, a rural. Um caso típico é o do agronegócio da soja que se expande na região de Cerrado no sul do estado, como parte de um dos projetos transformadores. Nesse exemplo, a integração da região de forma rápida nos circuitos do capital, em que a produção de soja é comercializada nas Bolsas de Valores de várias partes do mundo, se dá com a negação/desconhecimento das populações locais e, de forma exógena, se instala na região, principalmente no município de Balsas, onde há a polarização dos insumos técnicos, financeiros e estruturais para essa atividade. A microrregião Gerais de Balsas é a de maior produção de grãos de soja no estado e o município de Balsas aglomera as principais atividades empresariais ligadas ao agronegócio da soja.

Esse trabalho tem como um dos objetivos analisar os conflitos na microrregião Gerais de Balsas a partir dos avanços, permanências e a expansão da agricultura da soja. Outro objetivo é tentarmos compreender o contexto de expulsão e expropriação do campesinato, efetivada por uma dinâmica de expansão/desenvolvimento capitalista no espaço agrário.

\section{A construção do espaço capitalista}

Para Rui Moreira (2007), o espaço nasce da tensão contraditória entre localização e distribuição. Ele passa a ser resultado de um sistema de localizações recíprocas e interligadas que se dão por atos de seletividade em virtude da diversidade estrutural dos elementos. Milton Santos (1997) observou que o modo de produção da sociedade é o mesmo modo de produção de seu espaço, assim, sociedade, espaço e modo de produção caminham juntos na reprodução das relações sociais e, consequentemente, na análise que se faz deles. O caráter histórico e social da produção espacial é uma das principais causas dessa inseparabilidade.

A concepção exposta contrapõe-se a uma percepção empirista do espaço, que o vê na sua forma abstrata ao tê-lo sem relação com a história da sociedade que o produz. A Geografia desenvolvida por Vidal de La Blache se insere nessa perspectiva e Yves Lacoste fez uma forte crítica a essa corrente, ao descrever o método vidaliano na sua "Geografia Regional".

Lacoste (1988) observou o método de Vidal de La Blache, como uma forma apriorística de recortar as formas espaciais em determinadas regiões, 
pois considera que a região é fruto de uma sutil e lenta combinação das forças da natureza e do passado, sendo, dessa forma, uma permanência. Essa leitura empirista do espaço de Vidal de La Blache tem equívocos nas análises espaciais da sociedade. Alguns exemplos são apontados por Lipietz (1988), como a desagregação dos objetos em subobjetos regionais. A partir de tais observações, estabelece uma teoria da localização. O outro diz respeito à consideração de um espaço euclidiano, essencialmente o problema da bidimensionalidade e da superfície que se consome e não produz. O espaço se tornaria homogêneo e isótropo, neutro, e nele apenas se desenvolveriam os fatos econômicos.

O conceito de espaço em Moreira (2007) e em Santos (1997) evidencia as relações sociais, nas quais a natureza é modificada pelo homem através do trabalho. Assim, a produção do espaço se dá no âmbito das relações sociais, sendo produto do trabalho produzido socialmente. As formas sociais, os grupos, as relações sociais, os produtos de tais elementos são feitos a partir de um contexto de produção que contém forças produtivas e meios de produção. Há "a necessidade de não dissociar o produtor, o produzido e o contexto de sua produção" (Moraes, 2002, p. 21). Assim, a produção do espaço expressa determinações do modo de produção mediadas pelo movimento histórico-concreto da sociedade.

Esse movimento implica modificações na paisagem e nas funções dos lugares, que vão alterar a forma de o espaço se organizar. Milton Santos observou que "[...] cada lugar está sempre mudando de significação, graças ao movimento social: a cada instante as frações da sociedade que lhe cabem não são as mesmas" (Santos, 1992, p. 2).

Essas modificações na atualidade seguem demandas que podem ser percebidas com a análise da expansão e crescimento da produção de soja no sul do Maranhão. A inserção desse estado no mercado mundial, através da exportação de grãos e dos mecanismos da globalização, é típico desse processo que ocorre na escala global, mas a interferência espacial mais perceptível está no local.

Os cerrados localizados na microrregião Gerais de Balsas no sul do Maranhão transformaram-se nos últimos anos em espaços de reprodução da atividade sojicultora, principalmente por apresentarem fatores que propiciam a agricultura da soja, tais como terras planas e predominância de um relevo de chapadas que facilita a utilização de máquinas na colheita da soja, aumentando a sua produtividade. 


\section{Expropriação e apropriação do espaço pelo agronegócio no sul do Maranhão}

Com a Revolução Industrial, as noções de tempo e espaço ganharam novos significados. O tempo adquiriu nova significação para incorporar a distinção entre o tempo da natureza e o tempo do relógio. O primeiro, representando as tradições e os costumes, e a forte tendência para medição de períodos a partir do tempo dos acontecimentos rotineiros, os fatos do dia a dia etc.; o segundo associou-se às comunidades que se utilizam dos recursos naturais ainda de maneira tradicional. O modo de vida dessas comunidades se reproduz e rege formas de se relacionar e de se lidar com o tempo da natureza e com o espaço.

O espaço, como resultado do trabalho e da história da sociedade e sua configuração, ocorre a partir da correlação de forças presentes na sociedade e, dessa forma, ele passa a ser controlado por aqueles que conseguem a hegemonia de classe através de seu bloco histórico. $\mathrm{O}$ espaço é apropriado pelo modo de produção como elemento de sua reprodução e da reprodução da classe hegemônica, e, assim, ele passa a servir à acumulação de capital.

O arranjo espacial hegemônico reproduz as relações de produção capitalista, como o assalariamento, a acumulação de capital, a expropriação dos meios de produção das classes subalternas e a exploração do trabalho, para citar as suas características aparentes. Mesmo sobre o que se denominou "lugares de reserva" (Elias, 2006), o capitalismo exerce sua influência. O processo de reprodução do capitalismo, que acontece de forma contraditória no espaço, criando lugares dos circuitos rápidos do capital, e "lugares de lentidão" ou "lugares de reserva", é refletido no espaço através de formas, objetos espaciais, estruturas que se fixam a partir de um processo de seletividade espacial.

No caso específico do campo brasileiro, os espaços agrícolas do semiárido e dos cerrados nordestinos assumem papel de destaque nesse processo de reestruturação. O agronegócio, ou a moderna agricultura no campo brasileiro, especialmente a soja, é parte do processo de inserção do Brasil na divisão internacional e territorial do trabalho e do processo de mundialização do capital. O crescimento da cultura da soja é visível desde a década de 1970, e, no Maranhão, destaca-se a partir de 1990, como mostram os dois quadros a seguir. 
Segundo o Quadro 1, a produção de soja no Maranhão aumentou cerca de 147 \%, sobretudo no sul, na região polarizada pelo município de Balsas.

Quadro 1 - Evolução da produção da soja no período de 2000 a 2007 no Estado do Maranhão e na microrregião Gerais de Balsas.

\begin{tabular}{|l|c|c|c|c|c|c|c|c|}
\hline \multirow{2}{*}{ Local } & \multicolumn{8}{|c|}{ Produção de soja (t) } \\
\cline { 2 - 10 } & $\mathbf{2 0 0 0}$ & $\mathbf{2 0 0 1}$ & $\mathbf{2 0 0 2}$ & $\mathbf{2 0 0 3}$ & $\mathbf{2 0 0 4}$ & $\mathbf{2 0 0 5}$ & $\mathbf{2 0 0 6}$ & $\mathbf{2 0 0 7}$ \\
\hline Maranhão & 454.781 & 491.083 & 561.118 & 660.078 & 903.998 & 996.909 & 931.142 & 1.125 .094 \\
\hline Gerais de Balsas & 319.688 & 347.598 & 396.956 & 447.393 & 583.387 & 642.103 & 565.194 & 717.140 \\
\hline
\end{tabular}

Fonte: IBGE - Produção Agrícola Municipal (2009).

No Quadro 2, observamos que a área plantada sofreu um incremento de $115 \%$. Este fato ocorreu, principalmente, nas áreas de cerrado maranhense. No ano de 1996, no Maranhão, eram contados 3.965 tratores nos estabelecimentos agropecuários, e em 2006 esse número cresceu para 5.866 tratores, um crescimento de mais de 50\% (IBGE, 2009a).

Quadro 2 - Área colhida de soja no período de 2000 a 2007 no Estado de Maranhão e na microrregião Gerais de Balsas.

\begin{tabular}{|l|c|c|c|c|c|c|c|c|}
\hline \multirow{2}{*}{$\begin{array}{l}\text { Lavouras } \\
\text { temporárias }\end{array}$} & $\mathbf{2 0 0 0}$ & $\mathbf{2 0 0 1}$ & $\mathbf{2 0 0 2}$ & $\mathbf{2 0 0 3}$ & $\mathbf{2 0 0 4}$ & $\mathbf{2 0 0 5}$ & $\mathbf{2 0 0 6}$ & $\mathbf{2 0 0 7}$ \\
\cline { 2 - 9 } & 178.716 & 213.436 & 237.923 & 275.252 & 340.403 & 372.074 & 383.284 & 384.474 \\
\hline Maranhão & 126.370 & 150.312 & 168.677 & 187.101 & 216.774 & 238.552 & 239.050 & 239.050 \\
\hline Gerais de Balsas &
\end{tabular}

Fonte: IBGE - Produção Agrícola Municipal (2009).

Esse crescimento da produção de soja, perceptível através da análise das áreas plantadas e do uso de maquinário agrícola, aconteceu por meio de estrutura empresarial que se estabeleceu na região, comprando terras a preços baixos ou "grilando" grandes áreas. Segundo documento do Sindicato de Produtores de Balsas e da Prefeitura do Município, 307 empresas atuavam em 2002 no que se denominou de "Arranjo Produtivo de Balsas", sendo 26 com um porte acima dos 2.000 ha. Estas empresas atuavam em uma área de mais de 113 mil hectares, significando, nesse período, aproximadamente $44 \%$ da área total (Sindibalsas; Prefeitura Municipal de Balsas, 2005).

O avanço do agronegócio da soja é resultado, sobretudo, da territorialização de grandes empresas multinacionais como a Bunge e a Monsanto. 
A Bunge atua comprando a produção e subordinando os produtores a seus preços, sendo que estes vendem antecipadamente sua produção. Assim, uma das principais empresas relacionadas à produção e processamento da soja tem instalações no Maranhão, nos municípios de Balsas, Porto Franco, Riachão, Sambaíba, São Domingos do Azeitão, Tasso Fragoso e São Luís, com capacidade de processamento de aproximadamente $293 \mathrm{mil}$ toneladas (Bunge, 2009).

\section{A ideologia do desenvolvimento e a expansão da pobreza}

O processo contraditório de expropriação e apropriação do espaço pelo agronegócio da soja subsidiado pela política pública de investimentos do Estado brasileiro, através de vários projetos estatais, territorializa-se nas regióes do cerrado, especialmente a partir dos anos de 1990 no sul maranhense. Um exemplo disso são os financiamentos através do Banco Nacional de Desenvolvimento Econômico e Social (BNDES) que, entre os anos de 2002 e 2005, desembolsou aproximadamente R $\$ 40$ bilhões, ou seja, $25 \%$ de seus investimentos, em atividades relacionadas ao agronegócio. Somente no ano de 2005, o Banco desembolsou em torno de $53 \%$ de seus investimentos com a cadeia produtiva da soja (BNDES, 2007).

O agronegócio da soja, fruto do processo modernizador e da globalização dos cerrados, gera a criação de trabalho na região com a chegada de investidores. A combinação desses fatores traria desenvolvimento para o estado, pois estão relacionados a uma possível geração de renda para os trabalhadores da região. Mas, a consequência desse processo mais presente nesses municípios é a concentração de renda decorrente das atividades de cunho empresarial e de alta capitalização. Observamos, no Quadro 3, que o índice de Gini ${ }^{1}$ cresceu nos municípios da microrregião de Gerais de Balsas, isso indica que houve acumulação de riqueza por uma pequena parcela de indivíduos, provavelmente representados pelos produtores da soja e pelos empresários que nesses locais se instalaram para explorar a atividade sojicultora. No município de Tasso Fragoso, esse crescimento foi de aproximadamente $26 \%$; em Balsas, foi de mais de $28,5 \%$. 
Quadro 3 - Evolução do índice de Gini dos municípios da microrregião Gerais de Balsas/MA.

\begin{tabular}{|l|c|c|}
\hline \multicolumn{1}{|c|}{ Município } & $\mathbf{1 9 9 1}$ & $\mathbf{2 0 0 0}$ \\
\hline Alto Parnaíba & 0,60 & 0,69 \\
\hline Balsas & 0,56 & 0,72 \\
\hline Feira Nova do Maranhão & 0,49 & 0,62 \\
\hline Riachão & 0,52 & 0,63 \\
\hline Tasso Fragoso & 0,53 & 0,67 \\
\hline
\end{tabular}

Fonte: PNUD (2003).

O Produto Interno Bruto (PIB) do estado cresceu com a inserção da economia da soja e com os grandes projetos desenvolvimentistas. No ano de 2003, o crescimento do PIB foi de aproximadamente 5,32\%, representando o quinto maior crescimento no Brasil. O PIB per capita passou de R\$ 1.359,00 no ano de 1997 para $R$ \$ 2.748,00 em 2003. Como consequência do aumento nos indicadores de produção do estado, o Índice de Desenvolvimento Humano (IDH) também teve crescimento, passando da última posição com 0,636 no ano de 2000 para 0,680 em 2004 (Carneiro, Evangelista, Vieira, 2007).

Na microrregião Gerais de Balsas, também cresceu o IDH municipal na última década do século XX como mostra o Quadro 4. No município de Feira Nova do Maranhão, o aumento do IDH foi de 22,1\%, o maior da região. Em Balsas, o crescimento foi de 18,36\%.

Quadro 4 - Evolução do Índice de Desenvolvimento Humano dos municípios da microrregião Gerais de Balsas/MA.

\begin{tabular}{|l|c|c|}
\hline Município & $\mathbf{1 9 9 1}$ & $\mathbf{2 0 0 0}$ \\
\hline Alto Parnaíba & 0,554 & $\mathbf{0 , 6 3 6}$ \\
\hline Balsas & 0,588 & 0,696 \\
\hline Feira Nova do Maranhão & 0,466 & 0,569 \\
\hline Riachão & 0,488 & 0,591 \\
\hline Tasso Fragoso & 0,500 & 0,599 \\
\hline
\end{tabular}

Fonte: PNUD (2003).

Esse crescimento na região é associado à expansão da sojicultura e seguido, pelo resto do estado, de um crescimento associado a outras modalidades do agronegócio, como a extração de celulose e a carvoaria para o abastecimento da indústria siderúrgica no estado. Esse crescimento 
alia-se ainda aos grandes projetos da estrada de ferro Carajás e do complexo portuário da Ponta da Madeira no município de São Luís. Esse crescimento do IDH está mais relacionado ao aumento da produção de bens, do que propriamente à qualidade de vida da população. Isso é visível nas periferias da cidade de Balsas, onde as condições de vida da população mais pobre revelam inteira carência.

Outro elemento que se liga à expansão da soja é o número de pessoal ocupado na agropecuária na região onde ela se expande. $\mathrm{O}$ Quadro 5 pode induzir a conclusões equivocadas, se o analisarmos na perspectiva produtivista, negando as populações que existiam antes mesmo da chegada da economia da soja. Em relação ao Brasil, na forma absoluta, ocorreu um decréscimo no pessoal ocupado com grau de parentesco e sem grau de parentesco, No primeiro caso, o decréscimo foi quase de $6 \%$, demonstrando que as atividades relacionadas ao trabalho familiar na agropecuária tiveram uma queda no período de 1996 a 2006. Essa queda pode estar relacionada à saída do homem do campo, como também ao avanço do agronegócio que subscreve as atividades de nível familiar e comunitário e tem a necessidade de usar pouca mão de obra. Já o decréscimo da mão de obra ocupada na agropecuária sem grau de parentesco foi de $17 \%$ no período.

Um fato curioso é que a participação relativa do pessoal ocupado na agropecuária com grau de parentesco obteve um crescimento em relação ao pessoal ocupado sem grau de parentesco. Isso se dá pela incapacidade de o agronegócio, baseado na monocultura e na mecanização da agricultura, absorver mão de obra, fazendo com que haja um decréscimo na participação relativa, mesmo havendo expansão de atividades que utilizem mão de obra sem grau de parentesco, com base em relações mercantis de trabalho.

O mesmo processo ocorre nos dados relativos ao Nordeste e ao Maranhão, porém, com uma proporção diferente, acontecendo um decréscimo relativamente próximo um do outro. No Nordeste, há uma queda na variável com laço de parentesco de aproximadamente $6 \% \mathrm{e}$, na variável sem laço de parentesco, de $7 \%$. No Maranhão, a queda é de $24 \%$ e $28 \%$, respectivamente. Com a participação relativa nos dados gerais também ocorre processo parecido com o restante do país: a participação do pessoal ocupado na agropecuária com grau de parentesco sobe e sem grau de parentesco cai. 
Quadro 5 - Pessoal ocupado em estabelecimentos agropecuários - 1996 e 2006.

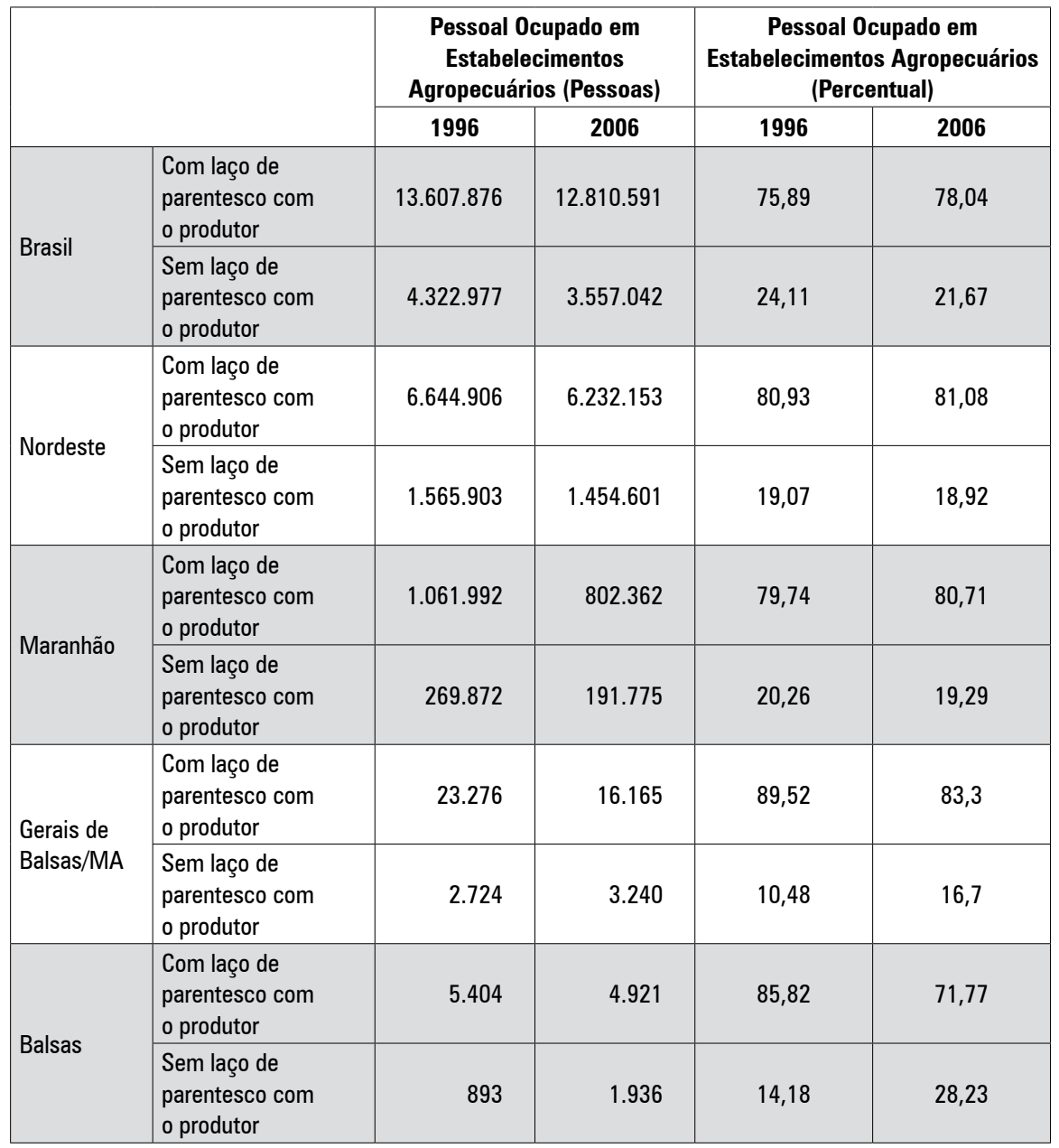

Fonte: IBGE - Censo Agropecuário 1996 e 2006 (2009).

Na microrregião Gerais de Balsas, o processo ocorreu de forma inversa. A variável do pessoal ocupado com grau de parentesco decresceu entre 1996 e 2006 em torno de 30\% enquanto a variável sem grau de parentesco cresceu aproximadamente 19\%. No município de Balsas, essa diferença é maior, um decréscimo de aproximadamente 8,9\% para a primeira variável e um crescimento exagerado de $116 \%$ para a segunda variável nesse mesmo período. 
Mesmo havendo um avanço do agronegócio e desterritorialização da agricultura camponesa, atividade que utiliza principalmente pessoal com grau de parentesco na agropecuária, a participação do pessoal ocupado sem grau de parentesco sofre um decréscimo, aumentando assim a participação de pessoas com grau de parentesco. Isto não ocorre nas regiões onde o agronegócio se expande fortemente, principalmente nos lugares que Denise Elias (2006) denomina "cidades do agronegócio", como é o caso de Balsas/MA. Nessas regiões, a participação do pessoal ocupado na agropecuária sem grau de parentesco cresceu, pondo em risco as atividades camponesas, baseadas na mão de obra familiar e comunitária.

Esse aumento de mão de obra sem laços de parentesco é resultado do aumento das relações trabalhistas que se alargam nas regiões de expansão do agronegócio. Esse aumento aconteceu com a modernidade e a mecanização agrícola que essa atividade ligada aos mercados internacionais traz consigo, dela necessitando para se reproduzir, já que está associada a uma intensa competitividade.

Sobre a "Modernização da Agricultura" no sul do Estado do Maranhão, Marcelo Carneiro, Leonardo Evangelista e Anderson Vieira explicam que:

a expansão da economia sojícola no sul maranhense trouxe consigo uma série de repercussões sociais (concentração de propriedade da terra) e ambientais (contaminação por agrotóxicos, destruição do cerrado) (Sousa Filho, 1995), no entanto a dimensão dessa expansão que mais atenção dos grandes meios de comunicação foi a da geração de empregos, fato esse que levou a designação dessa região como um novo ‘eldorado' de oportunidades. (Carneiro; Evangelista \& Vieira, 2007, p. 2)

Os dados sobre a intensidade de indigência e de pobreza na região indicam a diminuição da pobreza e a intensificação da indigência (Quadro 6). A intensidade da pobreza nos municípios da região Gerais de Balsa apresentou um decréscimo no período entre 1991 e 2000. No município de Feira Nova do Maranhão, o índice caiu de 71,12\% para 64,88, enquanto no município de Tasso Fragoso decresceu de 68,27\% para 59,27\%\%. O único município que apresentou um acréscimo na intensidade de pobreza nesse período foi Alto Parnaíba que, em 1991, registrou 57,33\% e, no ano de 2000, era de 62,9\%. O decréscimo no número de pobres não representa uma melhora significativa do nível de vida da população, tanto é que o índice de indigência nesse mesmo período aumentou em todos os municípios da 
região, exceto no município de Tasso Fragoso. No município de Balsas, a intensidade de indigência subiu de 40,55\% para 52,59\% e, em Feira Nova do Maranhão, de 55,51\% para 61,21\%.

Quadro 6 - Comparativo da intensidade de indigência e pobreza na microrregião de Gerais de Balsas.

\begin{tabular}{|l|c|c|c|c|}
\hline \multicolumn{1}{|c|}{ Município } & $\begin{array}{c}\text { Intensidade da } \\
\text { indigência, 1991 }\end{array}$ & $\begin{array}{c}\text { Intensidade da } \\
\text { indigência, 2000 }\end{array}$ & $\begin{array}{c}\text { Intensidade da } \\
\text { pobreza, 1991 }\end{array}$ & $\begin{array}{c}\text { Intensidade da } \\
\text { pobreza, 2000 }\end{array}$ \\
\hline Alto Parnaíba (MA) & 45,30 & 63,54 & 57,33 & 62,90 \\
\hline Balsas (MA) & 40,55 & 52,59 & 55,50 & 51,18 \\
\hline $\begin{array}{l}\text { Feira Nova } \\
\text { do Maranhão (MA) }\end{array}$ & 55,51 & 61,21 & 71,12 & 64,88 \\
\hline Riachão (MA) & 52,30 & 57,19 & 65,03 & 61,49 \\
\hline Tasso Fragoso (MA) & 55,71 & 50,47 & 68,27 & 59,27 \\
\hline
\end{tabular}

Fonte: PNUD (2003).

Sobre o Quadro 6, podemos afirmar, em primeiro lugar, que há saída para a população da situação de pobreza, mas ela continua estagnada na situação de indigência. Em segundo, podemos verificar que, apesar de parte da população dessa região sair da situação de pobreza, há aumento da população na situação de indigência.

Considerações para o debate

Os dados sobre o IDH, a renda per capita e o PIB do Maranhão indicam melhoras nos últimos anos, decorrentes principalmente do interesse dos investidores em reproduzir seu capital em um estado que ofereça terras para instalação de empreendimentos com valores irrisórios, impostos reduzidos e até anulados e disponibilidade de mão de obra barata. Esses investimentos se instalam no estado, sobretudo no formato dos grandes projetos, como ALUMAR, VALE, CELMAR, dentre outras empresas, ou através do agronegócio, tais como MARGUSA, BUNGE etc.

O agronegócio da soja vem crescendo num ritmo acelerado nas regiões planas do estado, como no cerrado, onde prevalecem planaltos de chapadas, propiciando essa atividade no formato atual da moderna agricultura excludente. Esse formato valoriza a utilização de pouca mão de obra. Se por um lado, ocorre um crescimento na utilização da mão de obra sem grau de parentesco, por outro diminui o seu uso grau de 
Artigo

parentesco. Esse último fato é consequência da expropriação campesina, que afeta as atividades que utilizam o trabalho comunitário e familiar, como é o caso da agricultura camponesa.

A expulsão e expropriação do campesinato, através da acumulação de terras e de renda pelos grandes empresários agrícolas, obrigam os camponeses a se aglomerarem nas periferias das cidades próximas, em situações precárias. A pobreza diminuiu, mas a indigência aumentou.

\section{Nota}

1 O índice de Gini é um indicador que avalia o grau de distribuição de renda, quanto mais próximo de zero maior igualdade na distribuição de renda, e quanto mais próximo de um, maior é a desigualdade.

\section{Referências}

BNDES. Informe setorial. n. 2. Janeiro: BNDES: 2007.

BUNGE. Nossa atuação. Disponível em: <www.bungealimentos.com.br/ fornecedor/mapa>; Acesso em: 4/5/2009.

CARNEIRO, Marcelo Sampaio; EVANGELISTA, Leonardo N.; VIEIRA, Anderson S. A "modernização" da agricultura no sul maranhense: um balanço 30 anos depois. 2007. (impresso).

ELIAS, Denise. Agronegócio e desigualdade socioespaciais. In: ELIAS, Denise \& PEQUENO, Renato (Org.). Difusão do agronegócio e novas dinâmicas socioespaciais. Fortaleza: Banco do Nordeste do Brasil, 2006.

IBGE. Censo agropecuário 1996-2006. Disponível em: <www.sidra.ibge.gov.br>; Acesso em: 7/5/2009a.

IBGE. Produção agrícola municipal. Disponível em: <http://www.sidra.ibge.gov. br>; Acesso em: 8/4/2009b.

LACOSTE, Yves. A geografia - isso serve, em primeiro lugar, para fazer a guerra. 7. ed. Campinas, SP: Papirus, 1988.

LIPIETZ, Alain. O capital e seu espaço. São Paulo: Nobel, 1988. (Coleção Espaços). MARANHÃO. Governo comemora exportação de semente de soja para a Venezuela. Disponível em: <http://www.ma.gov.br/2008/5/30/Pagina5543.htm>; Acesso em: 2/6/2008.

MOREIRA, Rui. O espaço e o contra-espaço: as dimensões territoriais da sociedade civil e do Estado, do privado e do público na ordem espacial burguesa. In: SANTOS, Milton; BECKER, Berta K. et al. Territórios, territórios: ensaios sobre o ordenamento territorial. 3. ed. Rio de Janeiro: Lamparina, 2007.

OLIVEIRA, Francisco de. Elegia para uma re(li)gião. SUDENE, Nordeste. Planejamento e conflito de classes. 3. ed. Rio de Janeiro: Paz e Terra, 1981. 
POCHMANN, Márcio \& AMORIM, Ricardo (Orgs.). Atlas da exclusão social no Brasil. 2. ed. São Paulo: Cortez, 2003.

MARANHÃO. Ministro garante a Jackson Lago investimento para o Maranhão. Disponível em: <http://www.ma.gov.br/2008/5/26/Pagina5467.htm>; Acesso em: 4/6/2008.

SANTOS, Milton. A natureza do espaço. Técnica e tempo, razão e emoção. São Paulo: Hucitec, 1996.

SANTOS, Milton. Espaço e método. 4. ed. São Paulo: Nobel, 1997. (Coleção Espaços).

SANTOS, Milton. Por uma outra globalização: do pensamento único à consciência universal. 10. ed. Rio de Janeiro: Record, 2003.

SINDIBALSAS; PREFEITURA MUNICIPAL DE BALSAS. Solicitações e reivindicações da classe produtora do Maranhão. Balsas, 2005. (Impresso).

Sávio José Dias Rodrigues - Mestre em Desenvolvimento e Meio Ambiente pela Universidade Federal do Ceará. Doutorando em Geografia pela Universidade Federal do Rio de Janeiro. Pesquisador do Núcleo de Estudos e Pesquisa em História, Educação e Cultura do Carmpo (NEPHECC) - UFMA.

Francisco Amaro Gomes de Alencar - Doutor em Sociologia pela Universidade Federal do Ceará. Professor Adjunto do Departamento de Geografia e dos Cursos de Pós-Graduação em Geografia e Prodema pela mesma Universidade. 